\title{
Autobiografia e Teoria do Discurso: uma possibilidade de desconstruir discursos das políticas curriculares de formação de professores no Brasil ${ }^{1}$
}

\section{Autobiographical and the Theory of Discourse: a possibility of deconstructing discourses of curriculum policies of teacher formation in Brazil}

\author{
Autobiografía y Teoría del Discurso: una posibilidad \\ de deconstruir discursos de políticas curriculares \\ para la formación docente en Brasil
}

Clarissa Bastos Craveiro ${ }^{2}$

DOI: http://dx.doi.org/10.20435/serie-estudos.v0i0.1474

\begin{abstract}
Resumo: Este estudo apresenta uma possibilidade de re-significar os discursos das políticas de formação de professores por meio da narrativa autobiográfica como um caminho de criticismo e mudanças nos discursos da escola. Discursos políticos têm procurado padronizar como os professores devem desempenhar suas funções de ensino e, assim, contribuir com a aprendizagem de seus alunos. Discordamos das propostas que tentam padronizar identidades dos professores. A partir de estudos já realizados no campo das políticas curriculares, por meio de um projeto de pesquisa em andamento, buscamos o desafio de dialogar com as propostas autobiográficas de William Pinar, Madeleine Grumet e Teresa Strong-Wilson re-visitando a compreensão de currere. Argumentamos com esses autores que a autobiografia é um processo associativo, cultural, constituído de conhecimento e prática. Por esse caminho, buscamos manter diálogos entre as pesquisas de política curricular da formação de professores, trazendo a abordagem discursiva da Teoria do Discurso. O desafio do diálogo proposto entre essas teorias é repensar os significados das políticas curriculares na escola com os professores.
\end{abstract}

Palavras-chave: formação docente; Pedagogia; perspectiva crítico-emancipatória.

\footnotetext{
${ }^{1}$ Parte deste texto foi publicada em uma versão em inglês no dossiê sobre autobiografia: "We are not alone - the subject of teachers and the auto/biographical in curriculum studies", organizada com a Profa. Dra. Teresa Strong-Wilson, na Transnational Curriculum Inquiry (TCI), v. 16, n. 2, 2019.

${ }^{2}$ Universidade Federal Fluminense (UFF), Angra dos Reis, Rio de Janeiro, Brasil.
} 


\begin{abstract}
This study presents a possibility of re-signifying discourses of curriculum policies for teacher formation from the autobiographical narrative as a path of criticism and change to the school's discourses. The policy discourses have sought to standardize how teachers should accomplish their teaching functions and thus contribute to the learning of their students. We have disagreed with these proposals that try to fix teacher identities. Based on studies already undertaken in the field of curricular policies, through a research project in progress, we seek the challenge of dialoguing with the autobiographical proposals of William Pinar, Madeleine Grumet, and Teresa Strong-Wilson re-visiting the understanding of currere. We argue with these authors that autobiography is an associative, cultural process, constituted of knowledge and practice. In this way, we seek to hold dialogues between the researches of curricular policies of teacher formation, bringing the discursive approach of Theory of Discourse. The challenge of the proposed dialogue between these theories is to rethink the meanings of curricular policies in school with teachers.
\end{abstract}

Keywords: autobiography; discourse; teacher formation.

Resumen: Este estudio presenta la posibilidad de re-significar los discursos de las políticas de formación docente a través de la narrativa autobiográfica como un camino de crítica y cambios en los discursos de la escuela. Los discursos políticos han tratado de estandarizar la forma en que los docentes deben realizar sus funciones de enseñanza y, por lo tanto, contribuir al aprendizaje de sus alumnos. No estamos de acuerdo con las propuestas que intentan estandarizar las identidades de los docentes. Con base en estudios ya realizados en el campo de las políticas curriculares, a través de un proyecto de investigación en curso, buscamos el desafío de dialogar con las propuestas autobiográficas de William Pinar, Madeleine Grumet y Teresa Strong-Wilson re-visitando la comprensión de currere. Argumentamos con estos autores que la autobiografía es un proceso asociativo, cultural, que consiste en conocimiento y práctica. A lo largo de ese camino, buscamos mantener diálogos entre la investigación de políticas curriculares de la formación docente, trayendo el enfoque discursivo a la Teoría del Discurso. El desafío del diálogo propuesto entre esas teorías es repensar los significados de las políticas curriculares en la escuela con los profesores.

Palabras clave: autobiografía; discurso; formación de profesores.

\title{
1 INTRODUÇÃO
}

Somos responsáveis pelas vidas que lideramos ${ }^{3}$. (William Pinar)

A proposta deste estudo tem como foco apresentar caminhos de apropriação autobiográfica em nossas pesquisas, no âmbito do nosso Grupo de Pesquisas Curriculares (GPeC) da Universidade Federal Fluminense (UFF), no campus de Angra dos Reis, Rio de Janeiro. Ainda que provisoriamente (LACLAU, 2011), optamos por compartilhar a nossa incompletude no sentido de fortalecer e unirmo-nos a outras pesquisas que também buscam descontruir propostas com sentidos

3 Tradução livre de "We are responsible for the lives we lead" (PINAR, 1976 apud PINAR; GRUMET, 2015). 
Autobiografia e Teoria do Discurso: uma possibilidade de desconstruir discursos das políticas curriculares de formação de professores no Brasil

padronizados para a escola e/ou para a formação de professores. Para isso, o nosso desafio tem como contexto a ser pesquisado o das escolas municipais de Angra dos Reis, localizada no Rio de Janeiro, Brasil. A opção pela proposta autobiográfica é caminhar em um sentido contrário ao da lógica hegemônica da centralização/ padronização curricular nacional (no Brasil, a centralização curricular vem ganhando força nas políticas curriculares desde a década de 1980 e, com mais ênfase, na década de 1990). Ou seja, possibilitar "uma conversa complicada", como diria Pinar (1995), com os professores em um dado contexto, compreendendo contexto "como um sistema de significação provisório" (LACLAU, 2011, p. 7).

Todavia, destacamos também que, neste momento, não é intenção principal de pesquisa nos aprofundarmos nos estudos de identidade docente, ainda que seja um aspecto central dos estudos autobiográficos no campo da formação de professores. O foco central é pensar caminhos para identificar discursos dissonantes aos discursos hegemônicos de padronização curricular que lutam por fixar-se na escola brasileira. Em outras palavras, buscamos, por meio da apropriação do currere, empoderar os discursos da difference nas discussões curriculares, em detrimento dos discursos da padronização curricular.

Concordamos e ressaltamos a atualidade das palavras de W. F. Pinar e M. R. Grumet (2015) em seu Prefácio de 1976:

Devemos derrubar a ideologia (discurso) ${ }^{4}$ do ambiente, a ideologia que diz, em qualquer complexidade, é o ambiente que determina a vida. Nós devemos trabalhar apesar das nossas circunstâncias: materiais, intelectuais, psicossocial. Nós devemos reivindicar o meio ambiente como a nossa terra; reivindicamos isso descaradamente. Essa é a nossa terra, e faremos dela o que quisermos 5 . (p. XV, tradução livre).

Sendo assim, organizamos este texto em duas seções: conversas com a Teoria do Discurso e com propostas autobiográficas e, por último, sinalizamos o caminho das últimas pesquisas com as quais o GePC tem se debruçado nos últimos tempos.

\footnotetext{
4 "In our understanding".

5 "We must overturn the ideology (discourse) of environment, the ideology which says, in whatever complexity, it is environment which determines life. We must work through our circumstances: material, intellectual, psycho-social. We must claim the environment as our land; we lay claim to it brazenly. This is our land, and we will make of it what we will", Pinar e Grumet (2015), em seu Prefácio de 1976.
} 


\section{INICIANDO A CONVERSA COM A TEORIA DO DISCURSO}

Pesquisas a respeito da produção da política curricular e da delimitação deste campo de estudo na formação de professores são recentes no Brasil, conforme destacam Lopes e Macedo (2008). Situam-se a partir da década de 1990 no Brasil e nos Estados Unidos e, com mais tempo, na Inglaterra, desde a década de 1980. Nessas produções, a temática da identidade docente é central na formação de professores e nos documentos curriculares que buscam orientar essa formação em um dado contexto histórico, por meio de indicações nacionais, internacionais ou locais, conforme temos discutido no Grupo de Pesquisa Políticas de Currículo e Cultura da Uerj no programa do Proped ${ }^{6}$, no GPeC e em publicações de Lopes, Macedo e Tura (2012). Tendo em vista que a temática da docência é crucial para as políticas curriculares de formação de professores, desde 2015 o GPeC tem buscado ampliar as análises dos sentidos das políticas cuja finalidade seja construir representações da formação docente e discente. Além desse aspecto, pretendemos também aprofundar os efeitos de tais políticas nas subjetividades, por meio de estudos do cotidiano escolar. Seja por meio de análises dos documentos oficiais, seja por meio da investigação autobiográfica e outros aportes teórico-metodológicos. A intenção dessas pesquisas e estudos é desenvolver articulações e negociações de sentidos que possam trazer contribuições ao Instituto de Educação de Angra dos Reis (IEAR) da UFF a partir do campo do currículo, ou seja, em diálogo com autores nacionais e internacionais que vêm se debruçando sobre o tema.

Destacamos também que, nas pesquisas sobre políticas de currículo, o foco na formação de professores marca o protagonismo docente, na medida em que esse agente é significado como a peça-chave nas mudanças políticas curriculares. É considerado como quem ressignifica o conhecimento, dissemina e transforma o discurso político-pedagógico nas várias instâncias educacionais. Esse espaço ora é significado pela omissão de sua atuação ou formação, remetendo a um discurso de culpabilização docente pelo fracasso dos alunos nas avaliações nacionais ${ }^{7}$ e internacionais (Common Core $^{8}$ ), ora marcado por um espaço de "endeusamento"

6 Programa de Pós-Graduação em Educação da Universidade Estadual do Rio de Janeiro (Uerj).

7 A esse respeito, sobre o currículo, o trabalho docente e a escola na linha accountability, ver Pereira, Costa e Cunha (2015).

8 Por exemplo, a iniciativa educacional de 2010, nos Estados Unidos, que estabelece Padrões 
Autobiografia e Teoria do Discurso: uma possibilidade de desconstruir discursos das políticas curriculares de formação de professores no Brasil

e que significa o professor como "parceiro" nas mudanças e nos projetos curriculares propostos pelos órgãos nacionais e internacionais. Em nossos estudos, entendemos que esse movimento de contínua produção discursiva de significados faz com que assumamos determinadas significações, produzindo simultaneamente "novas identificações globais e novas identificações locais" (HALL, 1997, p. 1).

Em estudos anteriores ${ }^{9}$, tenho buscado pensar nas políticas de formação de professores e nos endereçamentos de sentidos de tais políticas. O discurso hegemônico dessas políticas tem caminhado no sentido de buscar significar como os professores devem "ser" ou "estar aptos" às suas funções docentes e, dessa maneira, contribuir para o aprendizado de seus alunos. Em sentido contrário a esses discursos, tenho discordado dessas propostas com projetos de nação monoculturais, na medida em que se entende que esses projetos são construções discursivas e culturais. São os mecanismos de poder que sustentam essas políticas curriculares. Ou seja, há um "sistema de representação cultural" (HALL, 2006, p. 49) que cria significações ao mesmo tempo em que "constrói" identidades.

Até então, eu buscava, nessa perspectiva, a compreensão de que as propostas curriculares devem defender a diferença, o diálogo intercultural e a fluidez dos processos de identificação dos sujeitos a quem se destinam, o que é muito importante, pois qualquer fechamento que se aproxime de uma modelização acaba por forjar "padrões que trazem a negação do outro" (LOPES; MACEDO, 2008, p. 21). Buscava compreender o espaço dialógico como um processo contínuo de produção de sentidos com o olhar voltado para os estudos das políticas curriculares. E, como aponta Mouffe (2003), entendendo o reconhecimento de que os processos de identificação abrangem uma multiplicidade de elementos, o que permite uma porosidade das suas fronteiras, que poderia contribuir para a criação de condições de contextos plurais que valorizam a diversidade e o dissenso e, dessa forma, possibilidades de uma vida democrática a se conquistar.

Instigada a pensar nas políticas de formação de professores e nas repercussões das propostas de centralização curricular para a escola e para a formação de professores (CRAVEIRO; RIBEIRO, 2017), temos pensado caminhos para descons-

Estaduais e detalha o que os alunos do ensino fundamental e médio devem conhecer em disciplinas da língua inglesa e matemática, na conclusão de cada série escolar, tornou-se uma referência para a política brasileira.

9 Craveiro (2016, 2015 e 2014). 
truir propostas que sinalizem o fechamento de contextos plurais nesses espaços. Com esse intuito, apresentamos um estudo teórico como possibilidade de pensar caminhos de pesquisa, de mudança e de desconstrução de alguns discursos nas políticas curriculares para formação de professores e para a escola a partir do discurso autobiográfico e da Teoria do Discurso. Partimos do pressuposto de que as propostas curriculares para a formação do docente buscam fixar uma identidade específica com pretensão de definir, previamente, os modos de atuar desses atores sociais. Por exemplo, pesquisas realizadas por Freitas (2013), Craveiro e Freitas (2017), Craveiro e Oliveira (2015), Craveiro e Pugas (2013), que, apesar dos diferentes sentidos e oscilações destacados para o professor em discursos curriculares, sinalizam em comum o protagonismo docente.

Para nós, tal protagonismo docente na política curricular significa o professor como um agente social que ressignifica o conhecimento, disseminando-o e transformando o discurso político-pedagógico nas diversas instâncias educacionais, a fim de contribuir, assim, para a aprendizagem de seus alunos. Todavia, compreendemos que esse processo que por ora denominamos "ressignificação do discurso" é incontrolável, contingente e precário (LACLAU, 2009), apesar dos discursos centralizadores das propostas curriculares.

Nesse sentido, concordamos com Borges e Lopes (2017) de que as políticas curriculares pautadas pelas lógicas do controle, seja por conta de avaliações centralizadas, seja pelo controle da interpretação nas prescrições ou nas proposições curriculares, buscam centralizar os sentidos na formação dos professores quanto aos conhecimentos escolares a serem adquiridos, mas, longe de promoverem uma "qualidade da formação docente", acabam por "operar na cristalização de identidades" (p. 9). Todavia, apesar de operarem na lógica da "previsibilidade" por suposto "controle" no direcionamento de atividades escolares, estão aquém de controlar o processo discursivo-pedagógico dos professores.

Defendemos esse entendimento por compreender que todo processo discursivo está associado ao sentido social do seu contexto: “[...] o discurso é uma unidade complexa de palavras e ações, de elementos explícitos e implícitos, de estratégias conscientes e inconscientes" (LACLAU apud BURITY, 2008, p. 42). O discurso é também entendido como construção política de produção de sentidos e, por isso, é mais do que simplesmente a fala ou a escrita. Dessa maneira, compreende-se que a formação discursiva "é sempre um conjunto articulado, mas 
Autobiografia e Teoria do Discurso: uma possibilidade de desconstruir discursos das políticas curriculares de formação de professores no Brasil

heterogêneo, de discursos, ou seja, de sistemas de regras de produção de sentido" (LACLAU apud BURITY, 2008, p. 42) que hegemonizam um dado discurso, em um dado momento, dentro de uma pluralidade de sentidos. Para Laclau (2009), uma das características centrais das articulações é o seu caráter contingente, precário e provisório, por isso mesmo sujeito às diferentes demandas que se articulam e produzem novos discursos.

A partir desse entendimento discursivo, compreendemos que as produções curriculares envolvendo a formação de professores e suas práticas sociais no contexto escolar fazem parte de uma contínua produção de significados, fazendo com que nos identifiquemos com determinadas posições sociais produzindo simultaneamente "novas identificações globais e novas identificações locais" (HALL, 1997, p. 1). Por isso, é possível dizer que os discursos produzidos nos textos das políticas curriculares voltadas para a formação de professores convivem com diferentes discursos sociais e culturais que são reinterpretados, ao mesmo tempo em que recriam novos discursos. Nessa contínua produção de sentidos, a formação de professores é marcada por uma tendência a naturalizar certos sentidos para o currículo, estabelecendo uma interface entre discurso pedagógico e discurso de política curricular de formação de professores.

Consideramos importante esclarecer os aportes teóricos, de onde parte esta pesquisa, destacando o viés discursivo, por acreditar na potencialidade destes e sua contribuição para pensar aspectos curriculares. Entretanto, desde 2012, na conferência do International Association for the Advancement of Curriculum Studies (IAACS), realizada no Rio de Janeiro, e nas Atividades Programadas para os alunos do mestrado e doutorado da Uerj/Proped: Escola de Altos Estudos Dr. William Pinar, organizadas pelas professoras Alice Casimiro Lopes e Elizabeth Macedo, ainda como aluna do doutorado, já havia ocorrido a oportunidade de um primeiro contato com os estudos teóricos e a proposta autobiográfica do professor Pinar.

Todavia, em meio à escrita da tese, meus estudos focaram-se na apropriação teórica sobre a circulação de sentidos para o que se entende "ser professor", as diferentes significações acerca da identidade docente, o que pode aferir uma qualificação positiva ou não para a sua atuação pedagógica em relação ao que se supõe que a sociedade espera dessa atuação. Defendemos que esses sentidos não devem ser naturalizados como constituintes da identidade docente. São 
produzidos discursivamente nas relações sociais do contexto em que são geridos. Por isso, entender essa produção discursiva em dado contexto pode contribuir para desnaturalizá-los.

Se, por um lado, os discursos das políticas curriculares endereçadas para os professores buscam naturalizar determinados sentidos para o ser professor, como um ator social que vai reverberar em sua prática escolar conhecimentos e experiências; por outro lado e, ao mesmo tempo, o professor produz constantemente sentidos no contexto da prática escolar, com seus alunos e consigo próprio e, como ator social, traz consigo um repertório de experiências pessoais, que são constantemente ressignificadas nas interações sociais e subjetivas provenientes das articulações discursivas no contexto das suas práticas. Nesse sentido, destacamos com Scott (1991 apud Miller, J.; Macedo, E., 2018, p. 7) que, no

[...] caráter discursivo da experiência: '[...] não são os indivíduos que têm experiência, mas sujeitos que são constituídos pela experiência' (SCOTT, 1991, p. 779, tradução livre). A experiência é discursiva, o vivido só faz sentido dentro de uma ordem discursiva que produz aquilo de que fala (FOUCAULT, 2009)".

Destacamos que essa contínua produção de sentidos é discursiva no contexto da prática escolar na qual pensamos os processos de identificação e as constituições de experiência do professor, entendendo que "o social funciona como linguagem, é produção discursiva, sendo o discurso o limite de toda objetividade" (LACLAU; MOUFFE, 2011, p. 5). Acrescentamos que a experiência profissional do professor é discursiva e, sendo assim, produz continuamente construção dos processos de constituição identitária do professor. É nesse aspecto que buscamos uma negociação de sentidos com abordagem autobiográfica de Pinar (2015), no sentido de que, segundo o autor, "experiência" no campo do currículo, geralmente, fazia referência a atividades, reduzindo a significação de "experiência", por exemplo, como "experiência vivida" (tradução minha) ${ }^{10}$. Articulamos esse sentido também com Strong-Wilson (2008), ao referir-se a experiências autobiográficas discursivas como parte do processo de constituição identitária do professor, que mencionaremos na seção posterior.

Na mesma via, complemento o posicionamento teórico, esclarecendo que "[...] compreendemos contexto como um sistema de significação provisório,

10 "lived experience" (p. 24). 
Autobiografia e Teoria do Discurso: uma possibilidade de desconstruir discursos das políticas curriculares de formação de professores no Brasil

produzido por antagonismo e exclusão" (LACLAU, 2011 apud LOPES, CUNHA, COSTA, 2013, p. 398) e por identificações provisórias, em que muitos processos de significação são produzidos no "[...] campo das relações diferenciais das quais emergem todas e cada uma das identidades particulares" (LACLAU, 2011, p. 38, tradução livre) ${ }^{11}$. Em outras palavras, poderia significar contexto como um "fechamento" provisório de significações produzido por atores sociais, concordando e reafirmando com Laclau (2011) que é nos processos de identificação da formação docente e na incompletude de tal identidade que se constitui a provisoriedade discursiva do contexto social.

Esse processo encontra-se em contínuo movimento de antagonismo, de exclusão e de identificações de sentidos que são importantes na compreensão da constituição particular dos professores como atores sociais no contexto escolar que, a posteriori, articularemos com os discursos autobiográficos dos professores. A "incompletude" identitária que faz parte desse processo é o que Laclau (2011) denomina de "[...] resultado direto da sua emergência diferencial: nenhuma identidade particular pode emergir sem supor e proclamar a exclusão de outras, e esta exclusão constitutiva ou antagonismo é a mesma condição compartilhada de toda constituição de identidade" (p. 38, tradução livre) $)^{12}$.

Nesta pesquisa, acreditamos também ser interessante pensar na impossibilidade do controle no qual alguns discursos curriculares buscam endereçar para a ação e o pensar docente, como se fosse possível materializar os processos de identificação docente a partir das políticas curriculares padronizadoras. Em outras palavras, os discursos curriculares padronizados nos impulsionam a pensar na incompletude identitária, na impossibilidade do controle, em quais exclusões e antagonismos são produzidos discursivamente pelos professores nos contextos sociais aos quais estão imersos nas escolas com propostas curriculares centralizadoras. Esses interesses de pesquisa coadunam com o entendimento de que o processo narrativo/autobiográfico pode ser considerado um processo aberto, que se constitui no processo discursivo consciente e inconsciente do narrar, ao mesmo

11 "campo de las relaciones diferenciales de las cuales emergen todas y cada una de las identidades particulares" (LACLAU, 2011a, p. 38).

12 "[...] resultado directo de su emergencia diferencial: ninguna identidad particular puede emerger sin suponer y proclamar la exclusión de otras, y esta exclusión constitutiva o antagonismo es la misma condición compartida de toda constitución de identidad" (LACLAU, 2011a, p. 38). 
tempo em que exclui sentidos com quais não quer se identificar. Esse processo, denominado de metaficção, conforme Strong-Wilson (2017), identifica-se como literatura contemporânea, um processo de autorreflexão e de criação das histórias que "[...] refletem no seu próprio processo de criação como a história está sendo contada" (p. 161) ${ }^{13}$. É por essa via que compreendemos que os discursos autobiográficos, em constante construção, são discursos que não estão "fixos", terminados, fechados. Também concordamos com Miller e Macedo (2018) sobre o fato de que a pesquisa autobiográfica pode ser encarada como "o modo principal de interrogação e de pesquisa em currículo e, ao mesmo tempo, rejeitar a ideia de um sujeito auto-constituído" (p. 3), por conta de ser um processo de pesquisa que se constrói com o sujeito in loco.

Todavia, a busca por dialogar com a abordagem discursiva de Ernesto Laclau e as propostas autobiográficas a partir dos discursos dos professores no contexto de suas práticas curriculares serão sinalizadas na seção posterior, à medida que dou início ao diálogo entre essas duas abordagens. Entretanto destacamos desde já, o potencial dos discursos autobiográficos para pensar novos caminhos para a formação de professores em direção a propostas que respeitem a liberdade e a diferença na escola.

\section{DIALOGANDO COM A ABORDAGEM AUTOBIOGRÁFICA}

Nesta seção, sinalizo algumas possibilidades de diálogo entre a pesquisa que já vinha realizando e a proposta autobiográfica no sentido de potência para desnaturalizar discursos padronizados para a formação de professores e para as experiências curriculares dos professores. Ao discordar das propostas curriculares padronizadas para a formação docente e/ou o controle das atividades docentes (BORGES; CUNHA; CRAVEIRO, 2019), defendemos que as propostas autobiográficas de pesquisa na escola podem ser um caminho inverso a tal padronização, na medida em que as propostas autobiográficas são contextuais e valorizam o "self". É por essa via que buscamos nos aproximar dos discursos autobiográficos como possibilidade de compreensão dos processos de identificação da identidade docente e das experiências curriculares no contexto escolar. Também destaca-

13 "[...] reflects on its own process of creation as the story is being told" (STRONG-WILSON, 2017, p. 161). 
Autobiografia e Teoria do Discurso: uma possibilidade de desconstruir discursos das políticas curriculares de formação de professores no Brasil

mos, concordando com Miller e Macedo (2018), que, apoiadas em Scott (1991), imaginamos que a narrativa da experiência possa ser útil para o questionamento das normatividades que têm profundas implicações sobre "[...] como a diferença é estabelecida, como ela opera e de que forma constitui os sujeitos que veem o mundo e nele agem" (SCOTT, 1991, p. 777-8, p. 954, tradução livre). Acreditamos que a opção discursiva autobiográfica, ainda em construção, é uma entre as várias possibilidades de "escrita da própria vida" ${ }^{14}$, que, como Smith (2010, p. 18) admite, "não é um gênero ou forma unitária, 'autobiografia' [...] é sempre contingente, adaptável, fluida e dinâmica"15.

Sendo assim, compreendemos o discurso autobiográfico como uma história contada sobre a própria experiência, em meio a um processo narrativo e da própria representação, no qual, por meio das "rachaduras" oportunizadas pelos processos de reflexão em meio ao discurso, pode-se fazer brilhar ou interromper os caminhos habituais da narrativa (STRONG-WILSON, 2015). Nesse sentido, podemos dizer que os processos de identificação identitária dos professores, contingentes, fluidos e provisórios, assim se constituem, a partir das desestabilizações nas "jornadas" autobiográficas. Esse processo é comparado a uma "jornada" pela autora, pois desenvolve-se a partir de quatro momentos do currere ${ }^{16,}$ inicialmente elaborado por William Pinar e posteriormente apropriado por diferentes autores, como Madeleine Grumet, Teresa Strong-Wilson, Christian Ehret, David Lewkowich e Sandra Chang-Kredl.

Smith (2010) ressalta um aspecto interessante a respeito dos processos identitários, destaca as relações da identidade com o social, em que "os sujeitos se conhecem em seus idiomas porque a experiência é discursiva"17 (p. 12, tradu-

14 "self life writing".

15 " [...] is not a single unitary genre or form, 'autobiography' (...) and ever contingent, adaptable, fluid, and dynamic" (SMITH, 2010, p. 18).

${ }^{16} \mathrm{O}$ método do Currere é regressivo, progressivo, analítico e sintético. "Regressivo. O primeiro passo do método é regressivo. Uma volta ao passado, capturando como era, e pairando sobre o presente" (PINAR; GRUMET, 2015, p. 71); “Progressivo deriva do significado 'pro' que significa 'antes' e 'gradi' que significa 'dar um passo, ir' [...] olhamos para o que não é o caso, o que ainda não está presente" (p. 75); Analítico "descreve o presente biográfico, exclusive do passado e do futuro, mas inclui respostas a eles" (p. 77) e Sintético "juntos+tithenai-lugar. Coloque-os de lado. [...] Eu conceituo a situação atual. Eu sou colocado junto” (p. 79) (tradução livre).

17 "[...] subjects know themselves in languages because experience is discursive" (SMITH, 2010, 
ção livre), na medida em que nossas relações em vários contextos, no dia a dia, na troca de conhecimentos, conectam-se com outros atores sociais por meio da linguagem. Concordamos com a autora no sentido de que há um processo discursivo nas relações com o social e com os atores sociais, pois "organizações sociais e interações simbólicas estão sempre em fluxo; portanto, identidades são provisórias"18 (p. 18, tradução livre). É mister esclarecer que na abordagem discursiva, na qual nos identificamos, não compreendemos que as relações identitárias com o social produzam diferentes identidades particulares. Retomando a Laclau (2011), é na incompletude da identidade particular que processos articulatórios são buscados, todavia esse processo não constitui múltiplas identidades, mas sim múltiplos processos discursivos de identificação. E, assim, podemos dizer que "os sujeitos autobiográficos são, portanto multiplamente vulneráveis: à sua própria opacidade, à sua relacionalidade com os outros"19 (SMITH, 2010, p. 38, tradução livre).

Na esteira de Pinar e Grumet (2015), Strong-Wilson (2008), em um dos seus estudos sobre currículo, propõe uma possibilidade de reconstruir o entendimento do currículo a partir das histórias dos professores. As histórias iniciam o caminho do processo autobiográfico discursivo de crítica e de análise do "self" no contexto coletivo da memória (com pequenos grupos de professores), utilizando a literatura infantil conhecida pelos professores em sala de aula.

Por meio da sua apropriação teórica de currere, os professores constroem discursos constituídos a partir de suas histórias de vida e de memórias. Segundo Strong-Wilson (2008), tais histórias pessoais podem ser recolocadas (ressignificadas) com as histórias "públicas" da literatura infantil que são contadas na escola. Esse processo não se dá de imediato, pois as memórias são narradas, contadas aos poucos ou "em camadas" por meio do "método escavation" ${ }^{20}$, no qual as histórias

$$
\text { p. 12). }
$$

18 "[...] social organizations and symbolic interactions are always in flux; therefore, identities are provisional" (SMITH, 2010, p. 18).

19 "[...] autobiographical subjects, then, are multiply vulnerable: to their own opaqueness, to their relationality to others" (SMITH, 2010, p. 38).

20 "Método escavation" consiste em ouvir as histórias "em camadas", as histórias que vêm do contexto familiar e que são memorizadas desde a infância. Um caminho de produção de consciência crítica" (STRONG-WILSON, 2008, p. 5, tradução livre). 
Autobiografia e Teoria do Discurso: uma possibilidade de desconstruir discursos das políticas curriculares de formação de professores no Brasil

da infância são confrontadas com as subjetividades atuais dos professores e, nesse processo, podem deflagrar os "monsters" interiores ${ }^{21}$ de cada professor. Nesse caminho, a confrontação entre os discursos públicos e os pessoais possibilitam aos professores construírem a difference nos discursos curriculares. Strong-Wilson (2008) tem como foco, em seu estudo, descontruir as narrativas naturalizadas na escola que possam ferir a justiça social e que ultrapassam os espaços escolares.

Em outras palavras, dá importância às narrativas autobiográficas que são contadas por meio das memórias dos professores da sua formação docente, de suas experiências escolares em um processo de relembrar, de transmitir, de interpretar e de criticar os discursos hegemônicos que são repetidos e transmitidos na cultura da escola e, muitas vezes, naturalizados como próprios do ambiente escolar. Propõe-nos, por intermédio do processo autobiográfico do currere, a possibilidade de um caminho particular para re-experienciar os discursos narrados por meio do currículo escolar. O método escavation procura extrair fissuras ou abrir pensamentos com os professores no processo de construção da difference no currículo escolar.

Strong-Wilson corrobora Pinar (STRONG-WILSON, 2017), ao significar currere como um método de estudo, de engajamento intelectual e social, uma possibilidade para abrir caminho para aprender, para refletir, um espaço de agência por meio das estruturas da subjetividade.

Entre os estudos de Grumet (PINAR; GRUMET, 2015), gostaríamos de destacar o foco da autora na apropriação do currere como possibilidade de ressignificar as experiências da infância escolar ou do ambiente familiar, entendendo que essas experiências narradas poderiam fazer parte de alguns discursos disciplinares na educação. Grumet apresenta-nos algumas metáforas, como "casa"22 ou "robe

${ }^{21}$ Os monsters como uma metáfora, um processo do currere no qual o professor pode confrontar a sua imaginação com o contexto real e acomodá-lo pedagogicamente. O "outro" é a diferença ou algum conhecimento tradicional que poderá ser representado como "monstro" (STRONGWILSON, 2008, p. 5, tradução livre).

22 "[...] para muitos de nós, o local de nossas primeiras e mais pungentes experiências de medo e prazer, nojo e conforto, tédio e excitação, estavam em casa" (p. 74). "Agora o processo de seleção (memória), esta determinação é algo que importa, é muito importante para o currículo. [...] O conhecimento prático que trazemos conosco de casa permanece preso na memória, codificada em imagens, associações sensoriais, histórias e emoções. Alojado na intuição, este conhecimento prático é raramente estendido no nosso trabalho no mundo público porque é 
verde"23 (GRUMET, 1991), por exemplo, em que nos ilustra, a partir de suas histórias autobiográficas, aspectos da vida familiar que, de alguma forma, poderiam ser ressimbolizados ou reinterpretados no currículo, mas que nem sempre isso acontece, enquanto "nós tentamos conectar as crianças a um mundo que se recusa a ouvir as canções das nossas próprias conexões” (GRUMET, 1991, p. 84, tradução livre) ${ }^{24}$. Dessa forma, a autora nos convida a repensar na disjunção ou ruptura ideológica de Dorothy Smith entre conhecimento familiar e conhecimento escolar. Segundo Smith (1987, p. 54 apud GRUMET, 1991, p. 84), "[...] as ideias, imagens e símbolos com os quais nossas experiências ganham forma social não como aquela coisa flutuante neutra que chamam de 'cultura', mas como o que é produzido atualmente por especialistas e por pessoas que fazem parte do aparato da classe que mantém o controle sobre a sociedade"25 (tradução livre). Concordo com Grumet (1991) no sentido da influência dos discursos sociais na escola, compreendendo que o controle social é gestado por produções discursivas (LACLAU; MOUFFE, 2011).

Ao nos aproximarmos das diferentes apropriações do currere com Madeleine Grumet e Teresa Strong-Wilson, identificamos diferentes modos para compreender os processos de construção da identificação docente como singulares, provisórios e contextuais, o que, a meu ver, traz à tona a inviabilidade de propostas padronizadas para a escola. Desta forma, a autobiografia pode ser um caminho para interromper o habitual e para recuperar a intencionalidade profissional docente, utilizando-se do passado (memórias), trazendo as suposições e as futuras inten-

raramente ressimbolizado por meio de processos que o codificam para a reflexão e translação para outras configurações" (p. 75, tradução livre).

23 “Evitei o pessoal, assim como evitei o 'autêntico' e 'sincero' como descritores para esta prosa e para esse processo, e recorri a várias narrativas para abrir o leque, as contradições, e todos os robes - seda, brocado, orlon, rayon (bem embalados), terry, seersucker, veludo, couro, pena - o que aqueles estudantes poderiam encontrar para esse processo acadêmico" (p. 91, tradução livre).

24 "[...] we try to connect children to a world that refuses to hear the songs of our own connections" (GRUMET, 1991, p. 84).

25 "....] the ideas, images and symbols in which our experiences is given social form not as that neutral floating thing called culture but as what is actually produced by specialists and by people who are part of the apparatus by which the ruling class maintains its control over the society" (GRUMET, 1991, p. 84). 
Autobiografia e Teoria do Discurso: uma possibilidade de desconstruir discursos das políticas curriculares de formação de professores no Brasil

ções do contador de histórias (do narrador/professor) em direção aos espaços da difference na escola.

\section{O DESAFIO DA DESCONSTRUÇÃO DE DISCURSOS CURRICULARES HEGEMÔNICOS NO CONTEXTO DA AUTOBIOGRAFIA DOS PROFESSORES}

Até o presente momento, pesquisas no âmbito das políticas curriculares com os aportes da Teoria do Discurso têm contribuído para repensar os processos de identificação docente, analisando os diferentes discursos que são valorizados nos documentos curriculares e disseminados nos discursos político-pedagógicos de propostas em redes estaduais, municipais e particulares. Nessa abordagem discursiva, poderíamos significar que o poder de alguns discursos sobre outros são disseminados por grupos sociais por meio de sentidos hegemônicos discursivos, ou seja, alguns discursos são valorizados e ganham força em determinado contexto social, mediante o incentivo de grupos sociais. A predominância hegemônica de alguns discursos sobre outros pode ser compreendida com Chantal Mouffe (CRITCHLEY, S. et al., 2015) pois, conforme a autora, "um elemento particular assume a tarefa impossível da representação universal" 26 (tradução livre) (p. 62). Por isso, alguns discursos curriculares assumem uma representação universal, por exemplo, podendo ocasionar que uma determinada identidade ou perfil para o professor passe a ser valorizada, difundida ou até avaliada em determinado(s) contexto(s) social(is).

Nos estudos mencionados sobre os discursos autobiográficos, sinalizamos também a naturalização de algumas narrativas contadas nas experiências curriculares e que, muitas vezes, nem sequer são questionadas. Tais discursos, repetidos pelos atores sociais na escola, tornam-se hegemônicos e são transmitidos e disseminados no ambiente escolar. Diferentemente de Ernesto Laclau e Chantal Mouffe, cientistas políticos que trabalham com questões sociais relacionadas ao poder e a hegemonia, William Pinar, Madeleine Grumet e Teresa Strong-Wilson, não significam "a força" de alguns discursos autobiográficos que são repetidos na escola como relações de poder. Partem de um outro campo de pesquisa, como é o campo da fenomenologia ${ }^{27}$, trazendo a primazia de alguns discursos a partir

26 "[...] a particular element assumes the impossible task of a universal representation" (p. 61).

${ }^{27}$ A respeito da matriz fenomenológica da autobiografia, sugere-se a leitura de William Pinar e 
de alguns estágios do currere nos discursos autobiográficos estudados que, a meu ver, podem possibilitar um caminho de diálogo entre as apropriações da metodologia currere de Strong-Wilson (2008) com as quais me deparo agora, e as análises discursivas com alguns aspectos da Teoria do Discurso das quais já venho utilizando nas pesquisas já mencionadas.

Sendo proposta das pesquisas do GePC a abertura a negociações no campo metodológico curricular, valorizamos a diferença no desafio da articulação entre Teoria do Discurso e Discursos Autobiográficos e, ainda em reflexão, com Pinar e Grumet, escrevemos "para ajudar que professores examinem caminhos com os quais têm se movido com formas convencionais na expressão de suas próprias afirmações autênticas" (p. 101, tradução livre) para pensar questões curriculares e a formação de professores.

\section{REFERÊNCIAS}

BORGES, Veronica; CUNHA, Viviane Peixoto; CRAVEIRO, Clarissa. Curricular centralization policy in Brazil: a discursive perspective on academic researches. Transnational Curriculum Inquiry, v. 16, n. 1, p. 23-37, 2019.

BURITY, Joanildo Albuquerque. Discurso, política e sujeito na teoria da hegemonia de Ernesto Laclau. In: MENDONÇA, Daniel de; RODRIGUES, Léo Peixoto (Org.). Pósestruturalismo e teoria do discurso: em torno de Ernesto Laclau. Porto Alegre: ediPUCRS, 2008.

CRAVEIRO, Clarissa B.; RIBEIRO, W. G. Precisamos de uma Base Nacional Comum Curricular? Linhas Críticas, v. 23, p. 51-69, 2017.

CRITCHLEY, Simon; DERRIDA, Jacques; LACLAU, Ernesto; RORTY, Richard. Deconstruction and Pragmatism. London and New York: Routledge, 2015.

GRUMET, M. R. Curriculum and the art of daily life. In: WILLIS, George; Shubert, Willian $\mathrm{H}$. (Edit.). Reflections from the heart of educational inquiry: understanding curriculum and teaching through the arts. Estados Unidos: [s.I.], 1991.

HALL, Stuart. Da diáspora: identidades e mediações Culturais. Tradução de Adelaine La Guardiã Resende, Ana Carolina Escosteguy, Cláudia Alvarez, Francisco Rüdiger e Sayonara Amaral, Liv Sovik (Org.). Belo Horizonte: Editora UFMG, 2006.

Madeleine Grumet (2015), citada neste texto. 
Autobiografia e Teoria do Discurso: uma possibilidade de desconstruir discursos das políticas curriculares de formação de professores no Brasil

HALL, Stuart. A Centralidade da cultura: notas sobre as revoluções culturais do nosso tempo. Revista Educação \& Realidade, Porto Alegre, v. 22, p. 15-46, jul./dez. 1997.

LACLAU, Ernesto. Emancipação e diferença. Coordenação e revisão técnica geral, Alice Casimiro Lopes e Elizabeth Macedo. Rio de Janeiro: EdUERJ, 2011.

LACLAU, Ernesto; MOUFFE, Chantal. Hegemony and socialist strategy. Londres: Verso, 2011.

LACLAU, E. La razón populista. Buenos Aires: Fondo de Cultura Económica, 2009.

LOPES, A. C.; MACEDO, E. (Org.). Políticas de currículo no Brasil e em Portugal. Porto, Portugal: Profedições Lda, 2008.

LOPES, A. C.; MACEDO, E.; TURA, M. L. As representações sociais e os estudos de política de currículo para formação docente. In: PLACCO, V. M. N. S.; VILLAS BÔAS, L. P. S.; SOUSA, C. P. (Org.). Representações sociais: diálogos com a educação. SP: Champagnat/FC, 2012, p. 109-36.

LOPES, A. C.; BORGES, V. Currículo, conhecimento e interpretação. Currículo sem fronteiras, v. 17, p. 555-73, 2017.

LOPES, A. C.; CUNHA, E.; COSTA, H. C. Da recontextualização à tradução: investigando políticas de currículo. Currículo sem Fronteiras, v. 13, p. 392-410, 2013.

MILLER, J.; MACEDO, E. Curriculum public policies: autobiography and relational subject, Práxis Educativa, Ponta Grossa, v. 13, n. 3, p. 948-65, set./dez., 2018.

MOUFFE, C. La paradoja democrática. Barcelona: Gedisa Editorial, 2003.

PEREIRA, Talita Vidal; COSTA, Hugo Heleno Camilo; CUNHA, Érika Virgílio. Uma base à Base: quando o currículo precisa ser tudo. Revista Educação Pública, Cuiabá, v. 24, n. 56, p. 455-69, maio/ago. 2015.

PINAR, W.; GRUMET, M. Toward a poor curriculum. Kingston, NY: Educator's International Press, 2015.

PINAR, W. Curriculum theorizing: the reconceptualists. Berkeley: McCutchan, 1995.

STRONG-WILSON, Teresa. Bringing memory forward: storied remembrance in social justice education with teachers. New York: Peter Lang Publishing, Inc, 2008. 
STRONG-WILSON, Teresa. Phantom traces: exploring a hermeneutical approach to autobiography in curriculum studies. Journal of Curriculum Studies, v. 47, n. 5, 2015.

STRONG-WILSON, Teresa. Following one's nose in reading W. G. Sebald allegorically: currere and invisible subjects, Educational Theory, v. 67, n. 2, 2017.

STRONG-WILSON, T.; EHRET, C.; LEWKOWICH, D. \& CHANG-KREDL, S. (Ed.) Provoking curriculum encounters across educational experience: new engagements with the curriculum theory archive. New York: Routledge, 2020.

SCOTT, J. W. The evidence of experience. Critical Inquiry, v. 17, n. 4, p. 773-97, jun./ago. 1991. doi: https://doi.org/10.1086/448612

SMITH, Sidonie. Reading autobiography: a guide for interpreting life narratives. 2. ed. Paperback, July 2, 2010.

\section{Sobre a autora:}

Clarissa Bastos Craveiro: Doutora em Educação na Universidade do Estado do Rio de Janeiro (UERJ), doutorado sanduíche na Universidade do Porto (FPCEUP) na área de Currículo e Formação de Professores. Mestre em Educação pela Universidade do Estado do Rio de Janeiro (UERJ). Especialista em Modalidades de Intervenção nos Processos de Aprendizagem pela Pontifícia Universidade Católica. Graduada em Pedagogia pela Universidade de São Paulo (USP). Professora da Universidade Federal do Rio de Janeiro (UFF/IEAR). Líder do Grupo de Pesquisas Curriculares (GPeC). E-mail: clacraveiro@yahoo.com.br, Orcid: https://orcid.org/0000-0003-3392-7112

\section{Recebido em: 20 de julho de 2020}

Última revisão: 8 de setembro de 2020 Aprovado em: 10 de setembro de 2020 